\title{
PERHITUNGAN KEBUTUHAN IRIGASI PEMBIBITAN BATANG BAWAH KARET BERDASARKAN NERACA AIR DI SEMBAWA SUMATERA SELATAN
}

\author{
Calculation of Rubber Rootstock Irrigation Requirement Based on Water Balance \\ in Sembawa South Sumatera
}

\author{
Andi Nur CAHYO*, Charlos Togi STEVANUS, dan Afdholiatus SYAFAAH \\ Pusat Penelitian Karet \\ Jalan Raya Palembang - Pangkalan Balai KM 29 \\ Sembawa Banyuasin 30953 Sumatera Selatan \\ *Email : nurcahyo.andi@yahoo.co.uk
}

Diterima : 9 Juli 2020 / Disetujui : 21 Desember 2020

\begin{abstract}
Rubber planting materials demand reach around 83-85 million every years in 2019-2024 through Bun 500 Program. This program which is initiated by Directorate General of Estate Crop is a good opportunity for provider of rubber planting material. Water demand is one of crucial factor affect rubber rootstock growth, therefore the irrigation requirement must be calculated. The objective of the research was to determine the rubber rootstock net irrigation requirement to prevent water deficit. The results showed that based on $p F$ curve analysis on clay loam soil in Sembawa using 30\% Management Allowable Depletion (MAD) value, the soil water content must be maintained above 291,4 $\mathrm{mm}$ to prevent drought stress in plant. Based on water balance using 35 years climatic data in Sembawa, the depletion of soil moisture content during dry period in a normal year was within MAD range, hence irrigation was not required. In contrast, when El-Nino occur (in 2015), irrigation must be given at least 11.3; 59.2; and $76.5 \mathrm{~mm} /$ month on August, September, and October, respectively. For 2020 , it was predicted that irrigation was be not needed until August.
\end{abstract}

Keywords: Irrigation; rubber rootstock; water balance; water deficit

\begin{abstract}
Abstrak
Kebutuhan bibit unggul karet pada tahun 2019 - 2024 yang mencapai 83-85 juta per tahun melalui progam Bun 500 Direktorat Jenderal Perkebunan menjadi peluang usaha bagi penyedia bahan tanam karet. Untuk itu penangkar bibit harus mengupayakan agar pertumbuhan bibit karet menjadi optimal. Kebutuhan air merupakan salah satu faktor yang mempengaruhi pertumbuhan batang bawah sehingga kebutuhan irigasi di pembibitan karet perlu diperhitungkan dengan cermat. Kebutuhan irigasi suatu lahan dapat dihitung menggunakan neraca air lahan yang diperoleh dari data curah hujan dan evapotranspirasi potensial selama 35 tahun terakhir. Tujuan penelitian ini adalah untuk mengetahui kebutuhan irigasi bersih untuk batang bawah karet menggunakan neraca air sehingga defisit air dapat dihindari. Berdasarkan hasil analisis kurva pF untuk tanah lempung berliat di Sembawa dengan menggunakan nilai MAD 30\%, diketahui bahwa kandungan air tanah harus selalu di atas 291,4 mm agar tanaman karet tidak mengalami cekaman kekeringan. Berdasarkan perhitungan neraca air dengan menggunakan rerata iklim 35 tahun terakhir di daerah Sembawa, pada tahun normal penurunan kandungan air tanah masih dalam batas management allowable
\end{abstract}


depletion, sehingga tidak perlu dilakukan irigasi. Sebaliknya pada saat fenomena ElNino terjadi pada tahun 2015, irigasi bersih harus diberikan minimum sebesar 11,3; 59,2; dan $76,5 \mathrm{~mm} /$ bulan untuk bulan Agustus, September, dan Oktober berturutturut. Untuk tahun 2020, hingga bulan Agustus irigasi diperkirakan tidak perlu diberikan.

Kata kunci: Batang bawah karet; defisit air; irigasi; neraca air

\section{PENDAHULUAN}

Program pengembangan perkebunan komoditas tanaman karet melalui Direktorat Jenderal Perkebunan dalam menyiapkan 500 juta bibit unggul atau yang dikenal dengan program Bun 500 menjadi peluang usaha bagi penyedia bahan tanam karet. Rencananya program tersebut akan dilakukan dalam kurun waktu 6 tahun (2019 - 2024) dimana kebutuhan bibit unggul tiap tahunnya dapat mencapai 83 85 juta (Tribunnews, 2019). Untuk antisipasi permintaan bibit karet dalam jumlah besar tersebut, penangkar bibit harus mengupayakan agar pertumbuhan bibit karetnya optimal, sehingga permintaan bibit dapat terpenuhi dengan baik dari segi jumlah maupun ketepatan waktu penyediaan bibit.

Pada umumnya, bibit karet ditanam di awal atau saat musim penghujan untuk menekan tingkat kematian di lapangan, sehingga persiapan bibit karet harus sudah selesai pada saat musim kemarau (Suryaningtyas \& Boerhendhy, 2018). Untuk itu, pertumbuhan bibit batang bawah karet haruslah optimal dan dapat dilakukan okulasi sebelum musim kemarau. Hal ini dimungkinkan apabila digunakan biji batang bawah karet dari Sumatera Utara yang musim bijinya jatuh pada akhir tahun. Sebaliknya apabila digunakan biji karet dari Sumatera Selatan yang musim bijinya jatuh pada awal tahun, apabila akan dilakukan okulasi cokelat, batang bawah tersebut harus melewati musim kemarau sehingga pertumbuhannya terhambat (Thomas, 1995). Peta Overseas Development Administration (ODA) (1990) menunjukkan bahwa sebagian besar wilayah Sumatera Selatan mempunyai iklim 3 sampai 4 bulan kering/tahun. Jumlah curah hujan untuk tanaman karet adalah $100-150 \mathrm{~mm}$ setiap bulan untuk memenuhi kebutuhan air tanaman, dimana dengan curah hujan $<100$ $\mathrm{mm}$ merupakan bulan kering untuk tanaman karet (Wijaya, 2008). Dengan adanya 3 bulan kering berturut-turut setiap tahun akan menjadi kendala dalam penyediaan bahan tanam karet.

Efek musim kemarau adalah terjadinya defisit air pada tanaman. Defisit air adalah suatu keadaan di mana tekanan turgor dan potensial air sel tanaman menurun dan menyebabkan ketidaknormalan fungsi organ tanaman (Shao et al., 2008). Selain itu, secara fisiologis kekeringan dapat menyebabkan turunnya kandungan klorofil a/b, konsentrasi unsur hara, konduktansi stomata, fotosintesa, dan transpirasi, sehingga laju pertumbuhan dan produksi tanaman terganggu (Sun et al., 2011; RiveraMendes et al., 2016). Contohnya adalah fenomena El-Nino pada tahun 2015 menyebabkan penurunan pertumbuhan lilit batang PB 260 umur 3 tahun sebesar 65\% dan penurunan produksi BPM 24 menjadi 10 g/p/s (Saputra et al., 2016; Sahuri \& Cahyo, 2018).

Salah satu faktor yang mempengaruhi pertumbuhan batang bawah tanaman karet adalah ketersediaan air (Teh et al., 2018). Bibit batang bawah tanaman karet yang mengalami defisit air akan mengalami keterlambatan pertumbuhan dibandingkan dengan bibit batang bawah yang selalu tercukupi kebutuhan airnya. Penelitian mengenai efisiensi penggunaan air yang dilakukan oleh Cahyo et al., (2008) menunjukkan bahwa pada umur 28 minggu setelah tanam, diameter batang bawah karet yang mendapatkan interval penyiraman 14 hari sekali hanyalah sebesar 50\% dari diameter batang bawah tanaman yang mendapatkan interval penyiraman dua kali seminggu. Dengan semakin cepatnya pertumbuhan batang bawah tersebut, okulasi dapat dilakukan lebih cepat, sehingga permintaan bibit karet dapat lebih cepat terpenuhi. 
Mengingat pentingnya air pada pembibitan tanaman karet, kebutuhan irigasi di pembibitan karet perlu diperhitungkan dengan cermat, sehingga target produksi bibit tanaman karet dapat tercapai dengan baik. Untuk menghitung kebutuhan irigasi pada suatu lahan, dapat digunakan perhitungan neraca air lahan sehingga fluktuasi kandungan air tanah yang telah terjadi dapat diketahui. Selain itu dengan menggunakan data perkiraan iklim, perkiraan fluktuasi kandungan air tanah yang akan terjadi juga dapat diketahui, sehingga dapat dilakukan persiapan irigasi yang lebih matang. Penelitian ini bertujuan untuk mengetahui kebutuhan irigasi bersih untuk batang bawah karet menggunakan perhitungan neraca air lahan.

\section{BAHAN DAN METODE}

Penelitian ini dilaksanakan pada bulan April 2020 di Pusat Penelitian Karet, Sumatera Selatan. Data yang digunakan untuk perhitungan neraca air dalam penelitian ini adalah data $\mathrm{CH}$ (curah hujan, yang diperoleh dari Ombrometer tipe observatorium) dan evapotranspirasi potensial (ETo, diolah dari data evaporasi panci kelas A) selama 35 tahun terakhir yaitu periode tahun 1985 hingga 2019 yang diperoleh dari Stasiun Klimatologi Pusat Penelitian Karet Sembawa yang terletak pada koordinat $03^{\circ} 08^{\prime \prime}$ Lintang Selatan dan $104^{\circ} 18^{\prime \prime}$ Bujur Timur serta ketinggian $10 \mathrm{~m}$ di atas permukaan laut. Selain itu, juga digunakan data nilai kandungan air tanah pada kapasitas lapang dan titik layu permanen sesuai dengan tekstur tanah pada lokasi penelitian di daerah Sembawa, Sumatera Selatan. Selain rerata data $\mathrm{CH}$ dan ETo selama 35 tahun terakhir, dalam penelitian ini juga digunakan data perkiraan curah hujan empat bulan ke depan (Mei, Juni, Juli, dan Agutus) yang diunduh dari situs website BMKG (Badan Meteorologi Klimatologi dan Geofisika [BMKG], 2020).

Nilai kadar air kapasitas lapang dan titik layu permanen tanah di daerah Sembawa didapatkan dari data sekunder. Nilai tersebut didapatkan dengan menggunakan Pressure Plate Apparatus dengan tekanan 1/3 atm untuk kapasitas lapang dan tekanan 15 atm untuk titik layu permanen. Kemudian kadar air \% volume dihitung berdasarkan perkalian antara contoh berat tanah tiap tekanan dengan bobot isi(Stevanus et al., 2017).

Nilai curah hujan yang digunakan dalam penelitian ini adalah nilai curah hujan bulanan yang didapatkan dari akumulasi curah hujan harian selama satu bulan tertentu, sedangkan nilai evapotranspirasi potensial bulanan didapatkan dari akumulasi nilai evapotranspirasi potensial harian selama satu bulan tertentu. Nilai evapotranspirasi potensial harian tersebut tidak langsung didapatkan dari alat panci kelas A pada Stasiun Klimatologi Pusat Penelitian Karet Sembawa, namun diolah terlebih dahulu menggunakan rumus (1) berikut (Doorenbos \& Pruitt, 1977; Allen et al., 1998; Savva \& Frenken, 2002).

$$
\mathrm{ETo}=\mathrm{Kp} \times \mathrm{Epan}
$$

Keterangan (Remaks):

Eto = evapotranspirasi potensial (potential evapotranspiration, $\mathrm{mm}$ )

$\mathrm{Kp}=$ koefisien panci dengan nilai 0,85 untuk panci kelas A pada Stasiun Klimatologi Pusat Penelitian Karet Sembawa (Pan coefficient with the value as 0.85 for Pan Type $A$ at Climatology Station IRRI Sembawa)

Epan = evaporasi panci kelas A (Pan evaporation type A, $\mathrm{mm}$ )

Pendekatan terhadap nilai evapotranspirasi bibit batang bawah karet (ETc) yang ditanam di lahan yang mempunyai nilai evapotranspirasi potensial sebesar ETo, dihitung dengan rumus (2) (Doorenbos \& Pruitt, 1977; Allen et al., 1998; Savva \& Frenken, 2002).

$$
\mathrm{ET}=\mathrm{ETo} \times \mathrm{kc}
$$

Keterangan (Remaks):

Etc = evapotranspirasi tanaman (crop evapotranspiration, $\mathrm{mm}$ )

Kc = koefisien tanaman, sebesar 0,6 untuk seedling karet klon GT1 (Crop coefficient wuth the value as 0.6 for seedling rubber clone GT1) (Thomas \& Tambunan, 1996). 
Nilai evapotranspirasi tanaman yang didapatkan dari rumus di atas beserta nilai curah hujan kemudian digunakan untuk menghitung nilai kandungan air tanah neraca air yang dibuat dengan rumus (3) sebagai berikut(Nasir \& Effendy, 2000).

$$
\mathrm{KAT}=\mathrm{KL} \times \mathrm{k}^{\mathrm{a}}
$$

Keterangan (Remaks):

$\mathrm{KAT}=$ kandungan air tanah (soil water content, $\mathrm{mm}$ )

$\mathrm{KL}=$ kadar lengas pada saat kapasitas lapang (moisture content at field capacity, $\mathrm{mm}$ )

a = nilai absolut APWL (Accumulation of Potential Water Loss).

APWL adalah akumulasi hasil negatif dari $\mathrm{CH}-\mathrm{ETc}$

$\mathrm{k}=$ konstanta dengan nilai (constant with the value as follows (4)):

$$
\mathrm{k}=\mathrm{P}_{0}+\frac{\mathrm{P}_{1}}{\mathrm{KL}}
$$

Keterangan (Remaks):

$\mathrm{PO}=1,000412351$

$\mathrm{P} 1=-1,073807306$

Dari nilai kadar air tanah yang diperoleh, dapat dihitung nilai defisit kandungan air tanah dan nilai evapotranspirasi aktual (ETA). Nilai ETA adalah sama dengan ETc apabila nilai APWL $=0$, sedangkan apabila nilai $\mathrm{APWL} \geq 0$, nilai ETA dapat dihitung dengan menjumlahkan $\mathrm{CH}$ pada bulan ke-i dan nilai absolut dari perubahan kandungan air tanah pada bulan ke-i. Apabila dari hasil perhitungan tersebut nilai ETA $>$ ETc, maka nilai ETA dianggap sama dengan ETc. Dari hasil perhitungan tersebut, dapat ditentukan nilai defisit air dengan menghitung selisih dari ETc dan ETA (Djufry, 2015).

Dalam penelitian ini juga dilakukan perhitungan kebutuhan irigasi dengan menghitung jumlah air yang harus ditambahkan di lahan dari kandungan air tanah bulan tertentu hingga tercapai level air tersedia bagi tanaman di atas batas kandungan air tanah maksimum untuk dilakukan irigasi berdasarkan nilai $M A D$ (management Allowable Depletion). Nilai minimum kandungan air tanah yang harus dipertahankan atau nilai maksimum kandungan air tanah yang memicu dilakukannya irigasi tersebut dapat dihitung dengan rumus (5) sebagai berikut.

$\mathrm{KAT}$ minimum $=\mathrm{FC}-(\mathrm{AWC} \times \mathrm{MAD})$.

Keterangan (Remaks):

KAT minimum = kandungan air tanah minimum yang harus dipertahankan = Kandungan air tanah maksimum pemicu irigasi (minimum soil water content should be maintenated = maximum soil water content for irrigation initiation)

$F C=$ Kapasitas lapang (Field capacity)

$A W C=$ Kandungan air tanah tersedia (Available Water Content), yang merupakan selisih kandungan air tanah pada kapasitas lapang dan titik layu permanen.

$M A D=$ Penurunan kandungan air tanah yang diizinkan (management allowable depletion).

\section{HASIL DAN PEMBAHASAN}

Air merupakan salah satu komponen yang dibutuhkan dalam proses fotosintesa yang dilakukan oleh tanaman hijau (Taiz \& Zeiger, 2002). Oleh karena itu ketersediaan air dalam tanah akan sangat berpengaruh terhadap laju pertumbuhan dan hasil tanaman. Air dalam tanah tersedia bagi tanaman dalam rentang kapasitas lapang dan titik layu permanen. Jumlah air yang masuk ke dalam lapisan tanah apabila melebihi kapasitas lapang akan dialirkan ke tempat lain melalui proses perkolasi maupun seepage (Kirkham, 2014). Selain itu, di atas kapasitas lapang, air akan masuk ke dalam pori makro dan mikro sehingga akar tanaman menjadi kekurangan oksigen atau yang disebut dengan hipoksia sehingga tanaman kesulitan dalam mengambil air dari dalam tanah (Bartholomeus et al., 2008). Sebaliknya apabila kadar air pada lapisan tanah turun hingga di bawah titik layu permanen, tanaman tidak akan mampu mengambilnya, sehingga laju fotosintesa 
terhambat. Oleh karena itu fluktuasi kandungan air tanah berpengaruh nyata terhadap fluktuasi pertumbuhan dan hasil tanaman, termasuk tanaman karet. Fluktuasi kandungan air tanah pada suatu daerah penting untuk diketahui agar dapat dilakukan mitigasi sehingga kandungan air tanah di daerah tersebut tetap berada dalam rentang kapasitas lapang dan titik layu permanen (rentang air tersedia).

\section{Neraca Air Lahan Berdasarkan Rerata Data Iklim 35 Tahun Terakhir (1985 - 2019)}

Berdasarkan data sekunder tentang analisis kurva $\mathrm{pF}$ tanah di daerah Sembawa, didapatkan bahwa kadar air tersedia untuk daerah Sembawa adalah 15,20\%, dimana kadar air kapasitas lapang adalah 33,70\% dan titik layu permanen adalah 18,50\% (Stevanus et al., 2017). Hasil perhitungan kandungan air tanah dan defisit air untuk daerah Sembawa, Sumatera
Selatan berdasarkan data rerata $\mathrm{CH}$ dan ETo selama 35 tahun terakhir disajikan dalam neraca air pada Tabel 1 .

Berdasarkan hasil perhitungan neraca air pada Tabel 1, terlihat bahwa secara umum setiap tahun hanya terjadi defisit air selama satu bulan, yaitu pada bulan Agustus. Defisit air terjadi apabila ETA lebih kecil dari ETc (Djufry, 2015) yang berarti bahwa kandungan air tanah tidak cukup untuk dievapotranspirasikan secara optimal. Defisit air yang terjadi tersebut tidak cukup parah karena kandungan air tanah masih dalam batas Management Allowable Depletion (MAD), yaitu lebih dari 291,4 mm, sehingga tanaman masih dapat mengambil air dari dalam tanah. Pada lokasi penelitian ini, tanaman tidak dapat mengambil air dari dalam tanah apabila kandungan air tanah $\leq 185 \mathrm{~mm}$ yang merupakan titik layu permanen untuk tekstur tanah lempung berliat dengan kedalaman daerah perakaran $1 \mathrm{~m}$.

Tabel 1. Neraca air lahan untuk daerah Sembawa, Sumatera Selatan berdasarkan rerata data iklim bulanan selama 35 tahun terakhir (1985-2019).

Table 1. Water balance for Sembawa, South Sumatra based on monthly climate data average of the last 35 years (1985-2019).

\begin{tabular}{|c|c|c|c|c|c|c|c|c|c|}
\hline $\begin{array}{l}\text { Bulan } \\
\text { Month }\end{array}$ & $\mathrm{CH}$ & ETo & ETc & $\mathrm{CH}-\mathrm{ETc}$ & APWL & KAT & DKAT & ETA & DA \\
\hline Januari & 240,0 & 88,9 & 53,3 & 186,7 & 0,0 & 337,0 & 0,0 & 53,3 & 0,0 \\
\hline Februari & 231,8 & 84,6 & 50,8 & 181,0 & 0,0 & 337,0 & 0,0 & 50,8 & 0,0 \\
\hline Maret & 290,7 & 95,7 & 57,4 & 233,3 & 0,0 & 337,0 & 0,0 & 57,4 & 0,0 \\
\hline April & 265,3 & 95,1 & 57,1 & 208,2 & 0,0 & 337,0 & 0,0 & 57,1 & 0,0 \\
\hline Mei & 150,3 & 102,4 & 61,5 & 88,8 & 0,0 & 337,0 & 0,0 & 61,5 & 0,0 \\
\hline Juni & 114,5 & 100,3 & 60,2 & 54,3 & 0,0 & 337,0 & 0,0 & 60,2 & 0,0 \\
\hline Juli & 94,9 & 107,4 & 64,4 & 30,5 & 0,0 & 337,0 & 0,0 & 64,4 & 0,0 \\
\hline Agustus & 54,8 & 111,3 & 66,8 & $-12,0$ & $-12,0$ & 325,9 & $-11,1$ & 65,8 & 1,0 \\
\hline September & 88,0 & 112,5 & 67,5 & 20,6 & 0,0 & 337,0 & 11,1 & 67,5 & 0,0 \\
\hline Oktober & 201,6 & 109,6 & 65,8 & 135,8 & 0,0 & 337,0 & 0,0 & 65,8 & 0,0 \\
\hline November & 268,8 & 95,7 & 57,4 & 211,4 & 0,0 & 337,0 & 0,0 & 57,4 & 0,0 \\
\hline Desember & 296,0 & 84,5 & 50,7 & 245,4 & 0,0 & 337,0 & 0,0 & 50,7 & 0,0 \\
\hline $\begin{array}{ll}\text { Keterangan }(1 \\
\text { CH } & =\mathrm{cu} \\
\text { ETo } & =\mathrm{ev} \\
\text { ETc } & =\mathrm{ev} \\
\text { APWL } & =\mathrm{ak} \\
\mathrm{KAT} & =\mathrm{ka} \\
\text { DKAT } & =\mathrm{pe} \\
\text { ETA } & =\mathrm{ev} \\
\text { DA } & =\mathrm{de}\end{array}$ & $\begin{array}{l}\text { cs): } \\
\text { ujan (ra } \\
\text { anspiras } \\
\text { anspiras } \\
\text { asi kehi } \\
\text { gan air } \\
\text { han kan } \\
\text { anspiras } \\
\text { ir (wate }\end{array}$ & $\begin{array}{l}\text { falt) } \\
\text { potensia } \\
\text { tanamai } \\
\text { ngan air } \\
\text { nah (soi } \\
\text { ingan ai } \\
\text { aktual ( } \\
\text { deficit) }\end{array}$ & $\begin{array}{l}\text { potent } \\
\text { crop e } \\
\text { otensi } \\
\text { vater } \\
\text { tanah } \\
\text { tual ev }\end{array}$ & $\begin{array}{l}\text { evapotransp } \\
\text { otranspirati } \\
\text { accumulatio } \\
\text { ent) } \\
\text { l water cont } \\
\text { otranspiratic }\end{array}$ & $\begin{array}{l}\text { tion) } \\
\text { fpotentic } \\
\text { differen }\end{array}$ & er loss) & & & \\
\hline
\end{tabular}




\section{Neraca Air Lahan Berdasarkan Data Iklim Tahun E1-Nino (2015)}

Defisit air akan terjadi lebih parah pada tahun-tahun terjadinya fenomena ElNino seperti yang terjadi pada tahun 2015. Defisit air pada tahun 2015 tersebut dapat dilihat pada perhitungan neraca air yang tersaji pada Tabel 2 .

Pada tahun 2015 defisit air terjadi hingga empat bulan berturut-turut dengan puncaknya pada bulan Oktober yang mencapai 30,6 mm. Hal ini berarti bahwa tanaman karet hanya dapat melakukan transpirasi $30,6 \mathrm{~mm}$ di bawah nilai transpirasi yang optimal. Hal ini dapat terjadi karena kandungan air tanah pada bulan tersebut turun hingga berada di bawah MAD dan hampir mencapai titik layu permanen, yaitu sebesar 193,7 mm. Dalam keadaan tersebut tanaman karet mengalami cekaman kekeringan, sehingga menyebabkan pertumbuhan tanaman karet terhambat.

\section{Perkiraan Neraca Air Lahan Berdasarkan Perkiraan Data Iklim 2020 dan Perkiraan Data Iklim Empat Bulan Kedepan}

Penurunan pertumbuhan dan hasil tanaman karet pada saat terjadinya kekeringan tersebut sangatlah merugikan pengusaha perkebunan karet, baik pengusaha bibit maupun kebun produksi. Oleh karena itu, perlu dilakukan mitigasi untuk mengatasi masalah kekeringan tersebut. Untuk itu, diperlukan perhitungan fluktuasi kandungan air tanah untuk masa yang akan datang. Perhitungan fluktuasi kandungan air tanah tersebut dapat dilakukan dengan menggunakan perhitungan neraca air dengan mengambil perkiraan data curah hujan untuk beberapa bulan ke depan yang tersedia dalam situs BMKG (BMKG, 2020). Perkiraan curah hujan bulan Mei, Juni, Juli, dan Agustus 2020 tersaji dalam Gambar 1.

Dalam perhitungan ini diambil asumsi bahwa nilai ETo bulanan untuk

Tabel 2. Neraca air lahan untuk daerah Sembawa, Sumatera Selatan berdasarkan data iklim bulanan tahun El-Nino (2015).

Table 2. Water balance for Sembawa, South Sumatra based on monthly climate data of El-Nino year (2015).

\begin{tabular}{|c|c|c|c|c|c|c|c|c|c|}
\hline \multirow{2}{*}{$\begin{array}{l}\text { Bulan } \\
\text { Month }\end{array}$} & $\mathrm{CH}$ & ETo & ETc & $\mathrm{CH}-\mathrm{ETc}$ & APWL & KAT & DKAT & ETA & DA \\
\hline & \multicolumn{9}{|c|}{ 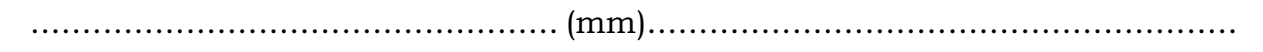 } \\
\hline Januari & 220,8 & 76,7 & 46,0 & 174,8 & 0,0 & 337,0 & 0,0 & 46,0 & 0,0 \\
\hline Februari & 271,5 & 72,6 & 43,6 & 227,9 & 0,0 & 337,0 & 0,0 & 43,6 & 0,0 \\
\hline Maret & 274,3 & 81,0 & 48,6 & 225,7 & 0,0 & 337,0 & 0,0 & 48,6 & 0,0 \\
\hline April & 242,0 & 79,0 & 47,4 & 194,6 & 0,0 & 337,0 & 0,0 & 47,4 & 0,0 \\
\hline Mei & 187,3 & 78,0 & 46,8 & 140,5 & 0,0 & 337,0 & 0,0 & 46,8 & 0,0 \\
\hline Juni & 123,1 & 75,5 & 45,3 & 77,8 & 0,0 & 337,0 & 0,0 & 45,3 & 0,0 \\
\hline Juli & 62,0 & 79,7 & 47,8 & 14,2 & 0,0 & 337,0 & 0,0 & 47,8 & 0,0 \\
\hline Agustus & 16,9 & 134,3 & 80,6 & $-63,6$ & $-63,6$ & 282,4 & $-54,6$ & 71,5 & 9,0 \\
\hline September & 14,0 & 122,0 & 73,2 & $-59,2$ & $-122,8$ & 239,6 & $-42,8$ & 56,8 & 16,4 \\
\hline Oktober & 0,6 & 128,5 & 77,1 & $-76,5$ & $-199,3$ & 193,7 & $-45,9$ & 46,4 & 30,6 \\
\hline November & 105,2 & 110,9 & 66,6 & 38,6 & 0,0 & 232,3 & 38,6 & 66,6 & 0,0 \\
\hline Desember & 251,7 & 115,5 & 69,3 & 182,4 & 0,0 & 337,0 & 104,7 & 69,3 & 0,0 \\
\hline
\end{tabular}

Keterangan (Remaks):

$\mathrm{CH}=$ curah hujan (rainfalt)

ETo = evapotranspirasi potensial (potential evapotranspiration)

ETc = evapotranspirasi tanaman (crop evapotranspiration)

APWL = akumulasi kehilangan air potensial (accumulation of potential water loss)

KAT = kandungan air tanah (soil water content)

DKAT = perubahan kandungan air tanah (soil water content difference)

ETA = evapotranspirasi aktual (actual evapotranspiration)

$\mathrm{DA} \quad=$ defisit air (water deficit) 

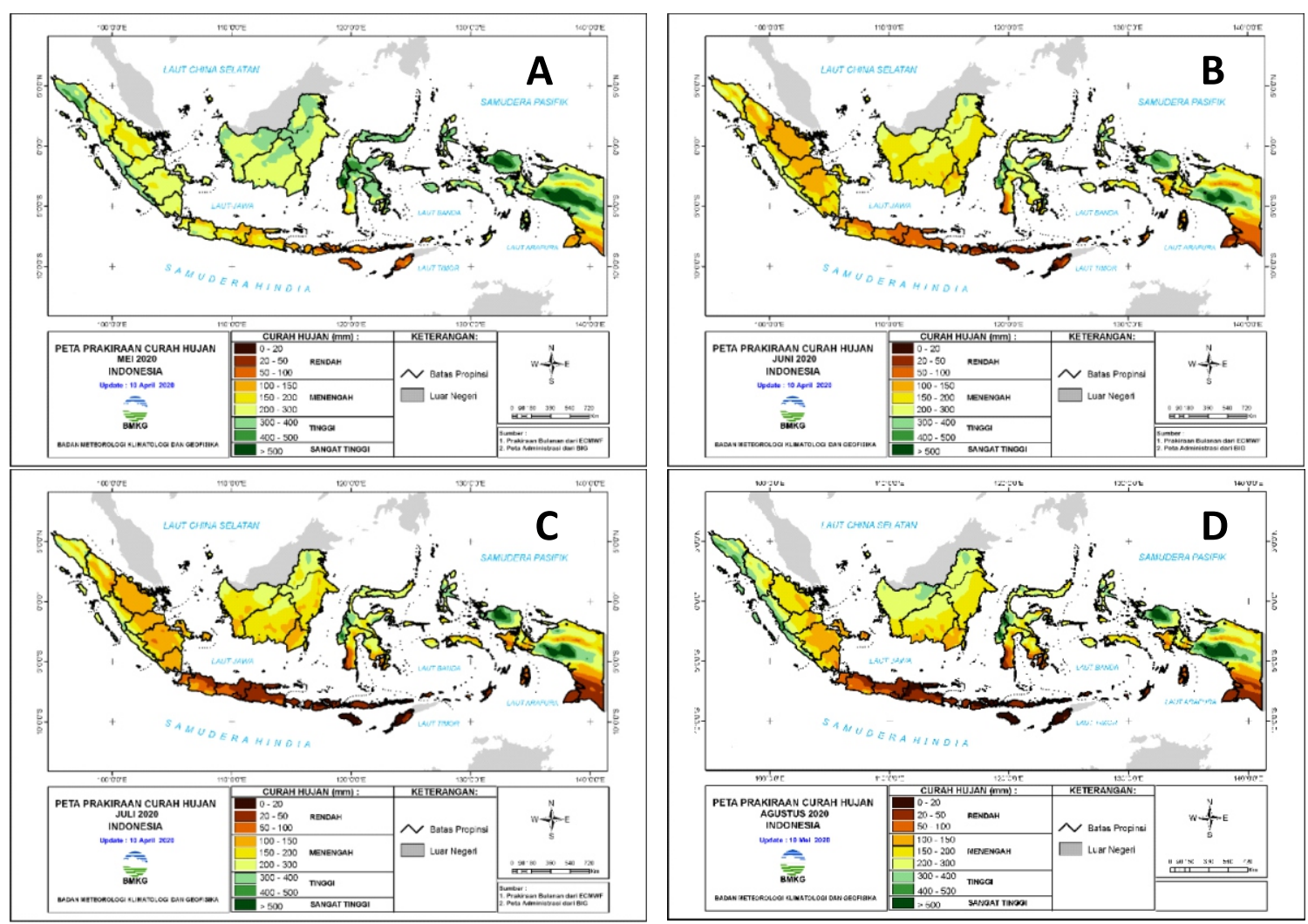

Gambar 1. Perkiraan curah hujan di Indonesia untuk bulan Mei (A), Juni (B), Juli (C), dan Agustus 2020 (D)

Figure 1. Rainfall prediction for Indonesia in May (A), June (B), July (C), and August (D)

Sumber (Source): BMKG (2020)

Tabel 3. Perkiraan neraca air lahan untuk daerah Sembawa, Sumatera Selatan tahun 2020. Table 3. Water balance prediction for Sembawa, South Sumatra in the year 2020.

\begin{tabular}{|c|c|c|c|c|c|c|c|c|c|}
\hline $\begin{array}{l}\text { Bulan } \\
\text { Month }\end{array}$ & $\mathrm{CH}$ & ETo & ETc & $\mathrm{CH}-\mathrm{ETc}$ & APWL & KAT & DKAT & ETA & DA \\
\hline Januari & 244,0 & 115,9 & 69,5 & 174,5 & 0,0 & 337,0 & 0,0 & 69,5 & 0,0 \\
\hline Febriari & 154,5 & 98,2 & 58,9 & 95,6 & 0,0 & 337,0 & 0,0 & 58,9 & 0,0 \\
\hline Maret & 485,3 & 124,2 & 74,5 & 410,8 & 0,0 & 337,0 & 0,0 & 74,5 & 0,0 \\
\hline April & 368,8 & 90,6 & 54,4 & 314,4 & 0,0 & 337,0 & 0,0 & 54,4 & 0,0 \\
\hline Mei & $250,0^{*}$ & $102,4^{* *}$ & 61,5 & 188,5 & 0,0 & 337,0 & 0,0 & 61,5 & 0,0 \\
\hline Juni & $125,0 *$ & $100,3^{* *}$ & 60,2 & 64,8 & 0,0 & 337,0 & 0,0 & 60,2 & 0,0 \\
\hline Juli & $125,0^{*}$ & $107,4^{* *}$ & 64,4 & 60,6 & 0,0 & 337,0 & 0,0 & 64,4 & 0,0 \\
\hline Agustus & $125,0^{*}$ & $111,3^{* *}$ & 66,8 & 58,2 & 0,0 & 337,0 & 0,0 & 66,8 & 0,0 \\
\hline \\
\hline \multicolumn{10}{|c|}{$\begin{array}{l}\text { Keterangan (Remaks): } \\
*\end{array}$} \\
\hline $\mathrm{CH}$ & \multicolumn{8}{|c|}{$\begin{array}{l}=\text { Rerata data bulanan selama } 35 \text { tahun terakhir }(1985-2019) \\
=\text { curah hujan (rainfall) }\end{array}$} & \\
\hline ETo & \multicolumn{9}{|c|}{$=$ evapotranspirasi potensial (potential evapotranspiration) } \\
\hline ETc & \multicolumn{9}{|c|}{$=$ evapotranspirasi tanaman (crop evapotranspiration) } \\
\hline APWL & \multirow{2}{*}{\multicolumn{9}{|c|}{$\begin{array}{l}=\text { akumulasi kehilangan air potensial (accumulation of } \\
=\text { kandungan air tanah (soil water content) }\end{array}$}} \\
\hline KAT & & & & \multicolumn{6}{|c|}{$=$ kandungan air tanah (soil water content) } \\
\hline DKAT & \\
\hline ETA & \multirow{2}{*}{\multicolumn{7}{|c|}{$\begin{array}{l}=\text { evapotranspirasi aktual (actual evapotranspiration) } \\
=\text { defisit air (water deficit) }\end{array}$}} & & \\
\hline DA & & & & & & & & & \\
\hline
\end{tabular}


tahun 2020 mendekati rerata nilai ETo bulanan pada 35 tahun terakhir, sehingga perkiraan nilai ETo untuk bulan Mei, Juni, Juli, dan Agustus tahun 2020 digunakan rerata nilai ETo pada bulan yang sama dari tahun 2009 hingga 2019. Hasil dari perhitungan neraca air untuk tahun 2020 tersebut tersaji pada Tabel 3.

Tabel 3 menunjukkan bahwa hingga bulan Agustus 2020 diperkirakan tidak terjadi defisit air, sehingga apabila dilihat dari segi ketersediaan air tanah, fluktuasi pertumbuhan dan produksi tanaman karet diperkirakan lebih kecil dari pada tahuntahun sebelumnya, kecuali apabila terdapat faktor-faktor lain yang turut berpengaruh misalnya hama dan penyakit, pemupukan, aplikasi stimulan, dan lain sebagainya.

\section{Kebutuhan Irigasi Pembibitan Batang Bawah}

Kebutuhan air irigasi dapat diperhitungkan dari neraca air yang memuat informasi mengenai perubahan kandungan air tanah. Dari fluktuasi perubahan kandungan air tanah tersebut, dapat diketahui waktu dan volume air yang optimal untuk diirigasikan ke lahan. Pada prinsipnya, air irigasi dapat diberikan ke tanaman apabila kandungan air tanah turun hingga mencapai ambang dimana tanaman mulai mengalami cekaman yang dapat mengakibatkan terhambatnya pertumbuhan dan hasil tanaman.

Air tanah tersedia untuk tanaman pada rentang kapasitas lapang hingga titik layu permanen. Pada rentang air tersedia tersebut, terdapat satu titik batas kandungan air tanah dimana apabila kandungan air tanah turun sampai di bawah batas tersebut, tanaman akan mengalami cekaman kekeringan. Nilai batas kandungan air tanah tersebut merupakan kadar air pada saat kapasitas lapang dikurangi dengan hasil perkalian dari nilai air tersedia dengan suatu faktor yang disebut Management Allowable Depletion (MAD). (Doorenbos \& Pruitt, 1977; Savva \& Frenken, 2002; Andales et al., 2015; Waller \& Yitayew, 2016). Apabila ketersediaan sumber air dan biaya irigasi terbatas, maka irigasi dapat diberikan dengan mempertimbangkan nilai $M A D$. Secara umum, kandungan air tanah harus selalu di atas nilai batas maksimum kandungan air tanah yang dihitung dengan nilai $M A D=30 \%$ untuk tanaman yang sensitif terhadap cekaman kekeringan dan $M A D=50 \%$ untuk tanaman yang toleran terhadap cekaman kekeringan (Savva \& Frenken, 2002; Waller \& Yitayew, 2016). Untuk tanaman karet, dalam perhitungan kebutuhan irigasi ini digunakan nilai $M A D=$ $30 \%$ karena pada umumnya tanaman karet adalah tanaman yang sensitif terhadap kekeringan, yang ditandai dengan terjadinya gugur daun pada saat musim kemarau (Ardika et al., 2011; Cahyo et al., 2011). Dengan menggunakan nilai $M A D=30 \%$ tersebut didapatkan nilai kandungan air tanah yang menjadi batas maksimum kandungan air tanah dalam rentang air tersedia untuk pemicu dilakukannya irigasi, yaitu kandungan air tanah sebesar 291,4 $\mathrm{mm}$. Hal ini berarti bahwa apabila perhitungan neraca air menunjukkan bahwa kandungan air tanah kurang dari 291,4 mm, irigasi harus segera dilakukan. Sebaliknya apabila kandungan air tanah masih di atas $291,4 \mathrm{~mm}$, irigasi belum perlu dilakukan karena tanaman belum mengalami cekaman kekeringan.

Pada Tabel 2, terlihat bahwa bibit batang bawah tanaman karet belum memerlukan irigasi karena penurunan kandungan air tanah pada saat musim kemarau masih berada dalam rentang $M A D$. Irigasi pada lahan pembibitan batang bawah tanaman karet diperlukan ketika terjadi fenomena El-Nino. Pada waktu terjadi fenomena El-Nino tahun 2015, kebutuhan air irigasi bersih minimum yang harus diberikan menurut perhitungan neraca air secara berturut-turut mencapai 11,3; 59,2; dan $76,5 \mathrm{~mm} /$ bulan untuk bulan Agustus, September, dan Oktober (Tabel 4).

Tabel 4 menunjukkan bahwa pada tahun 2015 terjadi bulan kering dari bulan Juli sampai Oktober, namun irigasi perlu dilakukan dari bulan Agustus sampai Oktober. Pada bulan Juli, surplus air tanah pada bulan sebelumnya berperan dalam menambah kandungan air tanah pada bulan Juli, sehingga menurut perhitungan neraca 
Tabel 4. Perhitungan kebutuhan irigasi bersih berdasarkan neraca air lahan untuk daerah Sembawa, Sumatera Selatan berdasarkan data iklim bulanan tahun El-Nino (1985 2019).

Table 4. Net irrigation requirement calculation based on water balance for Sembawa, South Sumatra based on monthly climate data of El-Nino year (2015).

\begin{tabular}{|c|c|c|c|c|c|c|c|c|}
\hline $\begin{array}{l}\text { Bulan } \\
\text { Month }\end{array}$ & $\mathrm{CH}$ & ETo & ETc & $\begin{array}{l}\mathrm{CH}+\mathrm{IR} \\
-\mathrm{ETc}\end{array}$ & APWL & KAT & $\begin{array}{l}\text { Kebutuhan } \\
\text { irigasi } \\
\text { minimum } \\
\text { Minimum } \\
\text { irrigation } \\
\text { requriement } \\
\text {........... }\end{array}$ & $\begin{array}{c}\text { Volume } \\
\text { irigasi } \\
\text { minimum } \\
\text { Minimum } \\
\text { irrigation } \\
\text { volume } \\
(000 \mathrm{~L} / \mathrm{Ha})\end{array}$ \\
\hline Januari & 220,8 & 76,7 & 46,0 & 174,8 & 0,0 & 337,0 & 0,0 & 0,0 \\
\hline \multirow{2}{*}{$\begin{array}{l}\text { Ebriari } \\
\text { Maret }\end{array}$} & 271,5 & 72,6 & 43,6 & 227,9 & 0,0 & 337,0 & 0,0 & 0,0 \\
\hline & 274,3 & 81,0 & 48,6 & 225,7 & 0,0 & 337,0 & 0,0 & 0,0 \\
\hline April & 242,0 & 79,0 & 47,4 & 194,6 & 0,0 & 337,0 & 0,0 & 0,0 \\
\hline Mei & 187,3 & 78,0 & 46,8 & 140,5 & 0,0 & 337,0 & 0,0 & 0,0 \\
\hline Juni & 123,1 & 75,5 & 45,3 & 77,8 & 0,0 & 337,0 & 0,0 & 0,0 \\
\hline Juli & 62,0 & 79,7 & 47,8 & 14,2 & 0,0 & 337,0 & 0,0 & 0,0 \\
\hline Agustus & 16,9 & 134,3 & 80,6 & $-52,3$ & $-52,3$ & 291,4 & 11,3 & 113,0 \\
\hline September & 14,0 & 122,0 & 73,2 & 0,0 & $-52,3$ & 291,4 & 59,2 & 592,0 \\
\hline Oktober & 0,6 & 128,5 & 77,1 & 0,0 & $-52,3$ & 291,4 & 76,5 & 765,0 \\
\hline November & 105,2 & 110,9 & 66,6 & 38,6 & 0,0 & 330,0 & 0,0 & 0,0 \\
\hline Desember & 251,7 & 115,5 & 69,3 & 182,4 & 0,0 & 337,0 & 0,0 & 0,0 \\
\hline $\begin{array}{ll}\text { Keterangan }(R \\
\text { CH } & =\text { cur } \\
\text { ETo } & =\text { eva } \\
\text { ETc } & =\text { eva } \\
\text { IR } & =\text { irig } \\
\text { APWL } & \text { aku } \\
\text { KAT } & =\text { kan }\end{array}$ & $\begin{array}{l}\text { aks): } \\
\text { hujan ( } r \\
\text { transpira } \\
\text { transpira } \\
\text { bersih ( } \\
\text { ulasi keh } \\
\text { angan air }\end{array}$ & $\begin{array}{l}\text { fall) } \\
\text { ootensial } \\
\text { tanaman } \\
\text { irrigation } \\
\text { ngan air } \\
\text { nah (soil }\end{array}$ & $\begin{array}{l}\text { otentic } \\
\text { rop eve }\end{array}$ & $\begin{array}{l}\text { vapotrans } \\
\text { transpirat } \\
\text { ccumulatic } \\
\text { nt) }\end{array}$ & ation) & 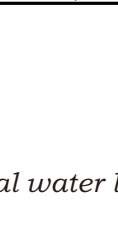 & & \\
\hline
\end{tabular}

air, kandungan air tanah pada bulan Juli masih di atas 291,4 $\mathrm{mm}$ dan tidak perlu dilakukan irigasi walaupun bulan Juli tersebut merupakan bulan kering. Sebaliknya pada bulan Agustus sampai November, irigasi perlu dilakukan karena hujan yang terjadi belum mampu mempertahankan kandungan air tanah untuk tetap berada di atas 291,4 $\mathrm{mm}$.

Untuk tahun 2020, menurut perkiraan curah hujan dari BMKG (BMKG, 2020) hingga bulan Agustus 2020 curah hujan masih di atas $100 \mathrm{~mm}(200-300 \mathrm{~mm}$ untuk bulan Mei dan 100-150 mm untuk bulan Juni, Juli, dan Agustus). Dari perhitungan neraca air dengan menggunakan perkiraan curah hujan tersebut yang dikombinasikan dengan nilai curah hujan dan evapotranspirasi potensial bulan Januari - April 2020, serta rerata evapotranspirasi potensial bulanan untuk bulan Mei - Agustus selama 35 tahun terakhir yang diamati di Stasiun Klimatologi Pusat Penelitian Karet Sembawa, diperkiraan hingga bulan Agustus 2020 tidak terjadi defisit air dan kandungan air tanah masih berada pada kapasitas lapang. Hal ini berarti bahwa diperkirakan hingga bulan Agustus 2020 belum perlu dilakukan irigasi untuk mencegah cekaman kekeringan pada bibit tanaman karet. 


\section{KESIMPULAN}

Berdasarkan data sekunder tentang hasil analisis kurva $\mathrm{pF}$ untuk tanah lempung berliat (clay loam) di daerah Sembawa didapatkan bahwa kadar air tersedia untuk daerah Sembawa adalah 15,20\%, dimana kadar air saat kapasitas lapang adalah $33,70 \%$ dan titik layu permanen adalah $18,50 \%$. Berdasarkan hasil tersebut, dengan menggunakan nilai $M A D 30 \%$, didapatkan bahwa kandungan air tanah harus selalu di atas 291,4 mm agar tanaman karet tidak mengalami cekaman kekeringan. Perhitungan neraca air dengan menggunakan rerata data iklim selama 35 tahun terakhir (mewakili keadaan iklim yang normal) menunjukkan bahwa irigasi bersih belum perlu diberikan pada tahun-tahun normal. Sebaliknya, pada tahun saat fenomena El-Nino terjadi pada tahun 2015, irigasi bersih harus diberikan minimum sebesar 11,3 ; 59,2 ; dan $76,5 \mathrm{~mm} /$ bulan untuk bulan Agustus, September, dan Oktober berturut-turut untuk menghindarkan tanaman dari cekaman kekeringan. Untuk tahun 2020, hingga bulan Agustus irigasi diperkirakan tidak perlu diberikan.

\section{DAFTAR PUSTAKA}

Allen, R.G., Pereira, L.S., Raes, D., \& Smith, M. (1998). FAO Irrigation and Drainage Paper No. 56-Crop Evapotranspiration (Guidelines for Computing Crop Water Requirements). Rome, Italy: FAO.

Andales, A.A., Chavez, J.L., \& Bauder, T.A. (2015). Irrigation scheduling: The water balance approach. Fact Sheet, (4.707), 1-6.

Ardika, R., Cahyo, A.N., \& Wijaya, T. (2011). Wintering and yield dynamics on various rubber clones and their relationship to soil water content. Jurnal Penelitian Karet, 29(2), 102-109. https://doi.org/10.22302/ ppk.jpk.v29i2.242
Bartholomeus, R.P., Witte, J.P.M., van Bodegom, P.M., van Dam, J.C., \& Aerts, R. (2008). Critical soil conditions for oxygen stress to plant roots: Substituting the Feddes-function by a process-based model. Journal of Hydrology, 360(1-4), 147-165. https://doi.org/10.1016/j.jhydrol.20 08.07.029

Badan Meteorologi Klimatologi dan Geofisika. (2020). Prakiraan Hujan Bulanan. Prakiraan Iklim. Jakarta, Indonesia: BMKG.

Cahyo, A.N., Ardika, R., \& Thomas. (2008). The effect of antitranspirant and soil conditioner on the growth and water use efficiency of PB 260 rootstock on several irrigation periods. Proceedings of Indonesian Soil Science Association Conference. Palembang, Indonesia: Soil Science Association.

Cahyo, A.N., Ardika, R., \& Wijaya, T. (2011). Water consumption and rubber production on various planting space arrangement system and their relationship with soil water content. Jurnal Penelitian Karet, 29(2), 110-117. https://doi.org/10.22302/ jpk.v29i2.243

Djufry, F. (2015). Pemodelan neraca air tanah untuk pendugaan surplus dan defisit air untuk pertumbuhan tanaman pangan di Kabupaten Merauke, Papua. Informatika Pertanian, 21(1), 1-9. https://doi.org/ 10.21082/ip.v21n1.2012.p1-9

Doorenbos, J., \& Pruitt, W.O. (1977). Crop Water Requirements. Rome, Italy: FAO.

Kirkham, M. B. (2014). Field Capacity, Wilting Point, Available Water, and the Nonlimiting Water Range. In Coombs, S.R. (Ed.), Principles of Soil and Plant Water Relations. Elsevier. https://doi.org/10.1016/B978-0-12420022-7.00010-0 
Nasir, A.A., \& Effendy, S. (2000). Water Balance Concept for Cropping Pattern Determination. In Nasir-Rizaldi-Boer, A. (Ed.), Agroclimatology Training Paper. Bogor, Indonesia: Geofisika dan Meterologi FMIPA-IPB.

Overseas Development Administration. (1990). The Land Resources of Indonesia-National Overview [Map]. London, England: ODA.

Rivera-Mendes, Y.D., Cuenca, J.C., \& Romero, H.M. (2016). Physiological responses of oil palm (Elaeis guineensis Jacq.) seedlings under different water soil conditions. Agronomia Colombiana, 34(2), 163-171. https://doi.org/10.15446/agron. colomb.v34n2.55568

Sahuri, S., \& Cahyo, A.N. (2018). Hubungan antara neraca air lahan terhadap produksi karet klon BPM 24. Widyariset, 4(2), 163. https: / / doi.org/ 10.14203/widyariset.4.2.2018.163172

Saputra, J., Stevanus, C.T., \& Cahyo, A.N. (2016). The Effect of El-Nino 2015 on the rubber plant (Hevea brasiliensis) growth in the experimental field Sembawa Research Centre. Widyariset, 2(1), 37-46. https://doi.org/10.14203/widyariset. 2.1.2016.37-46

Savva, A.P., \& Frenken, K. (2002). Crop Water Requirements and Irrigation Scheduling-Irrigation Manual Module 4. Rome, Italy: FAO.

Shao, H.B., Chu, L.Y., Jaleel, C.A., \& Zhao, C.X. (2008). Water-deficit stressinduced anatomical changes in higher plants. Comptes Rendus Biologies, 331(3), 215-225. https://doi.org /10.1016/j.crvi.2008.01.002
Stevanus, C.T., Ardika, R., \& Saputra, J. (2017). The effect of tillage and cover crop on soil physical properties and young rubber plant growth. Jurnal Penelitian Karet, 35(2), 139-148. https: / /doi.org/ 10.22302/ppk.jpk.v3 $5 \mathrm{i} 2.357$

Sun, C., Cao, H., Shao, H., Lei, X., \& Xiao, Y. (2011). Growth and physiological responses to water and nutrient stress in oil palm. African Journal of Biotechnology, 10(51), 10465-10471. https:/ / doi.org/10.5897/AJB1 1.463

Suryaningtyas, H., \& Boerhendhy, I. (2018). Persiapan Lahan dan Penanaman. In Vachlepi, A., Sahuri., Ismawanto, S., Stevanus, C.T., \& Aji, M. (Eds.), Saptabina Usahatani Karet Rakyat. Pelambang, Indonesia: Balai Penelitian Sembawa

Taiz, L., \& Zeiger, E. (2002). Plant physiology (3rd ed). Sunderland, UK: Sinauer Associates.

The, C.B.S., Husni, M.H.A., \& Sulaiman, Z. (2018). Plant growth, nutrient content and water use of rubber (Hevea brasiliensis) seedlings grown using root trainers and different irrigation systems. Pertanika Journal of Tropical Agricultural Science, 41(1), 251-270.

Thomas. (1995). Perhitungan kebutuhan air pada pembibitan karet. Warta Pusat Penelitian Karet, 14(3), 186-190.

Thomas., \& Tambunan, D. (1996). Pengaruh irigasi dan pemupukan terhadap pertumbuhan, intersepsi cahaya, dan efisiensi penggunaan cahaya pada semaian karet. Jurnal Penelitian Karet, 14(1), 16-26. 
Tribunnews. (2019). Kementan Siapkan 500 Juta Bibit Unggul Perkebunan Untuk Petani. Tribun-Timur.Com. https://makassar.tribunnews.com/2 019/05/16/kementan-siapkan-500juta-bibit-unggul-perkebunan-untukpetani

Waller, P., \& Yitayew, M. (2016). Irrigation and Drainage Engineering. Switzerland: Springer International Publishing.
Wijaya, T. (2008). Kesesuaian tanah dan iklim untuk karet. Warta Perkaretan, 27(2), 34-44 